\title{
RETHINKING PERFORMANCE MANAGEMENT PRACTICES IN LOCAL ADMINISTRATIONS? AN EVALUATION OF BV, CPA, AND WPI PRACTICES IN THE UNITED KINGDOM
}

Demokaan DEMIREL

\author{
Kocaeli University, Koaceli, TURKEY
}

e-mail: demokaand@gmail.com

\begin{abstract}
Performance is a fundamental tool that improves results oriented on public administration. Performance management applications have become very popular in public institutions over the past 20 years. Direct accountability to the political institutions and the public is ensured by defining the performance of public administrations according to their organizational goals and objectives. Local governments are using performance management practices to assess the quality of public services offered. In the United Kingdom, performance management practices at the local level were promoted under the leadership of the central government. However, there cannot be a certain standardization or stability in performance management applications. The Best Value (BV) regime was applied primarily in England and Wales. The system was later applied in Scotland in 2003. In 2002, Comprehensive Performance Assessment (CPA) Programme was introduced. Wales preferred to stay outside of this program. The Wales Programme for Improvement (WPI) has adopted self-assessment and holistic assessment. After 2009, the cost-effectiveness of local services was evaluated through comprehensive area assessments. This practice was abolished after 2010, adopting a governance approach based on the common negotiations of local actors. This study aims to evaluate the performance measurement systems applied in the local area in the United Kingdom.
\end{abstract}

Keywords: The Best Value, Comprehensive Performance Assessment, Comprehensive Area Assessment, Wales Programme for Improvement, United Kingdom.

JEL: H10, H83.

1

Introduction

Over the past two decades, there have been intense competitive pressures to improve the performance of public services and to reduce service costs. In this process, performance targets and indicators are set up to ensure the accountability to service users. Performance indicators are subject to more control to enable continuous improvement and cost savings.

Performance information obtained from performance management emphasizes the change in organizational qualities and organizational culture. In particular, the local performance indicators used in some way facilitate comparisons between public institutions. In the success of performance management, the communication system within the organization should also be processed correctly.

Performance management practices in the United Kingdom are depicted in a centralized up to down process. Local governments perform a rational sys- tem model based on performance measures and supported by audit processes.

The Best Value (BV) approach applied in the local administrations during the Labour Party is based on a partnership model in which the local administrations have a say in the development of the local services as well as the central government. Efficiency, effectiveness, and economic principles, as well as modernization policies implemented at the local level since 1999 with the BV, have become dominant in public administration with performance standards and external audit process. The comprehensive performance assessment (CPA) after the best practice has evaluated the performance of the local administrations in a five-point scale (from perfect to weak). After CPA, comprehensive area assessments have been introduced. Comprehensive area assessments appraised the performance of local governments holistically according to local area agreements. However, this practice was abolished in 2010 
and a governance approach has been adopted through voluntary programs aimed at leaders and administrators in local administrations to carry out performance assessments of senior staff in the local area.

This study is based on methodological and qualitative research methods. In the case of the United Kingdom, researches based on performance measurement systems in local governments and academic resources were used. Comparative analysis has been applied in evaluations of performance measurement systems. This study aims to evaluate the performance measurement systems applied to local governments in the United Kingdom. In the study, first the increasing importance of performance management in administrative structure and systems is mentioned. Then, the BV, CPA, and the Wales Program for Improvement are examined from the performance management practices in local governments.

The main problems of working are:

- What are the key elements in a successful performance management?

- What kind of difficulties can be encountered in performance measurement?

- What are the reasons for using performance indicators in the United Kingdom at the local level?

- How are the BV, CPA, and the Wales Programme for Improvement (WPI) approach to performance and accountability?

\section{Methodology}

This study provides an overview on how the research has been designed in order to develop the conceptual framework (Performance management in public administration, BV, CPA and WPI Approaches in the United Kingdom). The interlinked concepts in this article are the concept of performance management practices and performance evaluation systems. These concepts are investigated through literature review. Sources are selected by using search engines and databases such as Google Scholar, ProQuest, EBSCOhost, Scopus, Emerald Science, Oxford Journals, and Kocaeli University library database. Sources that are chosen have been in English, particularly from 2000 to recent years. The result of the academic literature study was categorized and the concepts were linked analytically. Finally, the results were synthesized and analyzed.

\section{Increasing Importance of Performance Management in Public Administration}

Performance management was primarily developed for the private sector. It consists of operational strategy and management techniques aimed at improving the performance of staff to observe corporate performance. Traditional performance management emphasizes the collective responsibility of organizational members to improve competitiveness and achieve team goals. Traditional performance management is the process of encouraging staffs to meet organizational developments to increase efficiency and effectiveness. Current developments in performance management focus on the economy, efficiency, effectiveness, and equity (Lin \& Lee, 2011, p.84). Performance management has gained great importance in public administration. Selected managers can improve political control in public services through performance management. Parliamentarians can provide accountability in the democratic system through performance management. Public administrators can use performance management to improve efficiency in administrative processes. Performance management has a directing influence to perceive the responsibilities of public officials (Lin \& Lee, 2011, p.92).

Performance management as a holistic process for management consists of four phases (Lin \& Lee, 2011, p.87):

- Planning: Deciding what to do and how to do it,

- Execution: Transform planned operations into actions,

- Monitoring: Checking completed projects, measuring results, and evaluating project progress,

- Evaluation: If the performance is considerably lower than the original schedule, plans and operational procedures are revised.

The performance management model is represented in a cyclical process. Affiliated entities and managers are invited by selected civil servants and senior executives to complete organizational objectives, set 
performance targets, and account for performance values measured (Nielsen, 2013, p.433).

The key elements of a successful performance management system are (Fryer, et al., 2009, pp.480-490) an organizational culture, stakeholder engagement, and continuous improvement that aims to identify and improve the performance management system with organizational strategies and existing systems, leadership, and continuous control (Table 1). Information on a successful performance management is an important element. The relationship between stakeholders, staffs, and partners should also be emphasized in the development of performance management.

Performance measures in public organizations re- quire the design of performance indicators, the establishment of management and control standards, and the observance of legality and responsibility issues (Lin \& Lee, 2011, p.94). The system must also be coherent with organizational culture and national or regional management traditions. In the system, all basic business responsibilities, including behaviors and results, should be evaluated. The evaluation should cover all review periods. The stability of the system must be ensured by minimizing errors (Auguinis, et al., 2013, pp.506-507). The process of monitoring performance should be integrated informally into the organizational culture. Clarification of expectations, informal feedback, and support in problem-solving improve the performance (Mueller-Hanson \& Pulakos, 2015, pp.14-16).

Table 1. Comparison of performance management styles

(Source: Pulakos, et al., 2012, p.15)

\begin{tabular}{|c|c|c|}
\hline Factors & $\begin{array}{l}\text { Performance management } \\
\text { (old concept) }\end{array}$ & $\begin{array}{l}\text { Performance management } \\
\text { (new concept) }\end{array}$ \\
\hline Organizational cooperation & Cascading targets & Mission statement \\
\hline Targets & $\begin{array}{l}\text { Specific, measurable, achievable, } \\
\text { realistic, and time-bound }\end{array}$ & $\begin{array}{c}\text { Increasing expectations based } \\
\text { on work }\end{array}$ \\
\hline Development & $\begin{array}{l}\text { Participation is off, } \\
\text { official training based }\end{array}$ & $\begin{array}{l}\text { A part of the daily routine, } \\
\text { based on guidance }\end{array}$ \\
\hline Feedback & Once or twice a year, perfunctory & Regular negotiations \\
\hline Performance rates & $\begin{array}{l}\text { Making cumbersome } \\
\text { and low-value decisions }\end{array}$ & $\begin{array}{l}\text { Simplified, standards based, } \\
\text { low impact }\end{array}$ \\
\hline Training & $\begin{array}{l}\text { Formal system requirements } \\
\text { for administrators }\end{array}$ & $\begin{array}{l}\text { Daily plans for managers } \\
\text { and staffs }\end{array}$ \\
\hline Policies and procedures & Large scale, documentation based & Fairly simplified \\
\hline Evaluation and monitoring & $\begin{array}{c}\text { Whether necessary steps are taken } \\
\text { or not }\end{array}$ & $\begin{array}{c}\text { Questionnaires that measure } \\
\text { behaviors, results, perceived } \\
\text { value }\end{array}$ \\
\hline
\end{tabular}

Program outputs in performance management and measurement of results is a requirement to encourage performance improvement. First of all, the institution has to define the program objectives. Second, the institution should measure outputs (specific outcomes that the organization achieves over a certain period of time). Third, the institution should choose desirable outputs (such as reductions in crime rates) that are not produced directly. Finally, the institution should conceptualize and perform procedures that will direct outputs if the outputs do not reach the targets (Schachter, 2010, p.554). The most important 
first step in creating a high-performance culture is to assess the position of the organization. Managers and employees are expected to adopt a new mentality of performance management. Staffs must understand their roles and contributions to the mission. Expectations should be clearly formulated and feedback should be provided to the staff. Feedback must be made to the personnel. The contribution should be made to the personal development of the staff (Pulakos, et al., 2012, pp.6-7).

Performance measurement can be seen as a decisionmaking system. Performance measurement is a collection of decisions made by organizations, teams, people who measure performance, and decision makers who benefit from performance measurement knowledge. There are two models in this regard: design model and usage model. In the design model, different norms related to individual measurement systems are associated with specific possibilities and interpretive projects. In the usage model, organizational actors have a common sense of performance measurement.

Performance measurement is more about information that includes explicit and implicit dimensions in which organizational performance is driven. Performance measurement information and its information perspective on organizational use require a dynamic budgeting process and mutual interaction.

Organizational performance measures have certain consequences. Members of the organization use performance measurement information to either maintain the status quo or change it by transforming institutional qualifications (Vakkuri and Meklin, 2006, pp.238-242). There are also some challenges in performance metrics. Performance rates usually do not lead to sufficient pay differentials among staffs. Formal performance management systems often try to justify poor performance rates.

Most institutions have a separate system for poor performers (Pulakos, et al., 2012, p.4-5), as the main performance management system does not have enough current rating information. Even if things happen within groups in most organizations, performance management systems focus on individual performance and do not consider teamwork (Auguinis, et al., 2013, pp.504).
Performance measurements can lead to measurement myopia at the expense of long-term consequences. It can emphasize local goals to achieve global goals. It can take into account the performance dimensions that are measured more than the unmeasured performance dimensions. Different situations in which flexibility is limited and innovation is blocked may arise. Performance data may be falsified or misrepresent performance. This is due to the difficulties in quantitatively measuring performance in the public sector (Cuganesan, et al., 2014, p.281).

Deciding what to measure and how to measure, it is important to evaluate the data and explain the results. In this regard, four types of performance indicators are used (Stevens, et al., 2006, cited by Fryer, et al., 2009, p.481):

1) Output (how much was it produced?)

2) Prosperity (value provided to the end user)

3) Performance (how are services produced?)

4) Mixed indications containing the other three.

It is thought that the performance indicators will facilitate benchmarking at the local level in public administration. According to this, performance indicators will solve problems arising from the lack of standardization related to performance identification, calculation, and analysis of acquired values (Galera, et al., 2008, p.257). However, technical, systematic, or involvement issues related to performance management are also present.

Technical problems include collecting, interpreting, and analyzing indicators and data. Systematic problems are the adaptation of existing systems to the performance system. The absence of multiple stakeholder relationships or customer interest and the indifference of decision makers and top management levels are some of the relational issues. Top performers should be maintained to overcome these problems.

Determining the preconditions in the first step requires forming the mission and strategic goals of the organization. In the second step, the manager and the staff decide on what needs to be done through the performance plans.

Organizations must develop and maintain individual development plans for top performers. Such plans should be established during the planning of the or- 
ganizational performance management system and revised at the stage of performance reviews.

Organizations should also use performance management to question the relevance and meaning of the work of top performers (Augunis, et al., 2012a, pp.612-614).

\section{$4 \quad$ Performance Management in Local Government and Applications in the UK}

Within the scope of new public management in the United Kingdom, the development of performance management followed a top-down process to improve control and accountability. The development and evaluation of performance management in local governments is described by central government reforms that encourage an instrumental and a managerial focus on external pressures and performance measurement. The importance of performance measurement, quality systems, control, and inspection in the United Kingdom is supported by a mechanistic rational system model (Sanderson, 2001, pp.297$300)$.

There are many reasons to use performance indicators at local level. Most local governments use performance indicators to identify their strengths and weaknesses. A second reason is that performance indicators provide corrective information on managerial weaknesses. The third reason is that if there is a possibility to compare with organizations with similar characteristics, the benefits of performance indicators are increasing. Fourth, determining how to select performance indicators, how to achieve service quality, what are the best ways to measure different services will increase administrative effectiveness (Galera, et al., 2008, p.242).

Despite all of these benefits, problems can arise in the implementation of performance indicators in local administrations, such as defining standard performance indicators for institutions, determining the necessary calculation techniques when values are found, and selecting criteria to analyze values (Galera, et al., 2008, p.245).

To overcome these problems, performance information should be accurate and up to date and should be followed regularly, including benchmarks, stand- ards, and objectives. Comparative analyses should be systematically used to describe the performance of the public administration. Performance should be reported to senior management, service users, elected councilors, and public (Midwinter, 2008, p.452).

The most important first step in creating a highperformance culture is to assess the position of the organization. Managers and employees are expected to adopt a new mentality of performance management. Staffs must understand their roles and contributions to the mission. Expectations should be clearly formulated and feedback should be provided to the staff. Feedback must be made to the personnel. The contribution should be made to the personal development of the staff (Pulakos, et al., 2012, pp.67).

Performance rates, required documentation, and determination of objectives are not sufficient for an effective performance management system alone. For this reason, negative perceptions of performance management are increasing because of the rigid workflows that require many operations and approvals (Pulakos, et al., 2012, pp.6-7).

According to Pulakos and Hanson (2015, pp.51-55), performance management systems have weakened the link between daily jobs and behaviors that affect performance (such as communicate about expectations, providing informal feedback, and gaining experience for staff). In this respect, it has failed to achieve performance goals and is not generally preferred by institutional managers and employees. Performance management, which started with periodic activities, has failed to guide behavioral and relational factors related to effective performance over time.

Administrators cannot be engaged in performance management alone. Performance management should be viewed as a result of the inter-party interaction. In the performance management reform, a system approach that takes into account the corporate talent management strategy is needed. The formal performance management system should be assessed for attributes such as commitment, highlevel job descriptions, and leadership development. 
An effective performance management reform consists of a five-step plan (Pulakos \& Hanson, 2015, pp.56-69):

1) Changing plan: Evaluate the current situation and develop a performance management strategy. The planning stage requires a deep analysis of organizational values, culture, and strategic priorities.

2) Modernize the current system: Remove unnecessary low-value jobs. Systemic modernization focuses on finding the right preferences for each organization to direct its specific goals, cultures, and needs.

3) Motivate change: Change mentality related to performance management. The purpose of this step is to train the workforce that will add value to performance management, especially professionals in the field of human resources.

4) Stable change: Provide change through behavioral training. The strategy used for change must be harmonized with the experience of the learning process.

5) Evaluate: To indicate attitudes, performance, and influence of the organization's output. Evaluation and feedback integrate effective performance management into the organizational culture.

Besides, adaptation to business definitions and organizational goals should be achieved. Training programs should add value to employees and reduce distortions. Behaviors and outcome-based performance management at the individual and collective level (team, department, and unit) should be undertaken. Performance feedback should be done with a power-based approach that enables employees to use their strengths to achieve successful performance. Attention should be paid to the results of the performance management process through the sharing of awards (Auguinis, 2012b, pp.387-388).

Under this heading, the performance management techniques that will be experienced in local governments in the United Kingdom will be referred.

\subsection{The Best Value}

The BV has come together in the Modern Local Government White Book: In Touch with the People. It was enforced by the Local Government Act of 1999 for local governments in United Kingdom and Wales. BV is intended to make a real and positive difference in local services (DETR, 1998). The BV consists of 12 principles (DETR, 1999):

- Local authorities should consider the public as customers and taxpayers,

- Performance plans support the local accountability process,

- The BV covers more services than compulsive competitive tendering,

- There is no obligation to privatize the services or to offer them by tender,

- The BV is about the quality and efficiency of local services as well as economy and efficiency,

- Competition is one of the key tools of performance plans and $\mathrm{BV}$,

- The central government establishes the basic framework and national standards for the provision of services,

- Local targets take into account interadministration benchmarks and national objectives,

- National and local targets are organized according to performance information,

- Control processes include comparisons of performance information and integrity. Controllers report on the results reached openly by the BV,

- If the local authority fails to achieve the BV, the Ministry will intervene with the recommendation of the audit committee,

- Ministry intervention should be in proportion to failure.

The BV concerns the concepts of value planning, value engineering, and value analysis, customer value from private sector management techniques. In addition, the increase in the performance measurement has strong links with performance assessment, stakeholder engagement, and joint strategic management. According to this, all municipal councils have to establish new performance targets and save up to $2 \%$ annual efficiency.

The BV regime distinguishes the performance of local administrations. Failed administrations are exposed to more centralized control. Administrations that are coasting or striving are kept under close review and control. Successful administrations are 
subject to less control and increase their financial resources (Martin, 2002a, pp.130-133).

Some methods have been used to obtain the BV results (Boyne, et al., 2001, pp.45-46):

\section{1) Performance plans}

The BV obliges the preparation of annual performance plans and that these plans contain current and historical information. The purpose of performance plans is to ensure accountability internally or externally. Performance plans provide local governments with developing strategies for internal and external stakeholders, planning their current performance, and publicly disclosing their performance (Boyne, et al., 2002, pp.692-700). Although local people have shown inadequate interest in these plans, preparation and distribution of the plans have taken a long time and the plans have been subject to close control. This practice was abolished after 2002 because it did not contribute to the development of performance (Bovaird, 2008, p.331).

2) BV inspections

It is based on the review of all functions of local governments within five-year periods.

\section{3) Activity plans}

The information obtained from the reviews forms the basis for the preparation of detailed abstract and transparent action plans.

The BV approach has four steps (Harris, 2005, p.5):

- Inquiry: Why and how a service is supplied,

- Benchmarking: Benchmarking performance to see how better the service can be achieved,

- Consultation: Identifying the expectations of local taxpayers and service users,

- Competition: Providing the best service delivery in a fair and transparent manner.

The BV is applied to all local administration services. Local authorities have encouraged competition by using techniques such as competitive tendering and joint ventures. In addition, local authorities issued annual performance reports reporting past performance and identify future goals according to local performance indicators (Martin, 2000, p.211).

As a result, high-performance and striving councils have acquired new flexibilities and freedoms, such as trading. The rest were subjected to direct central intervention by strict regulation. Services have been transferred to other administrators or private sectors (Martin, 2002b, p.304). The BV is a framework that empowers local governments for performance management. It is based on the external control and inspection process with performance standards and progress targets defined by the central government (Sanderson, 2001, pp.307-309). Accordingly, the audit committee will examine the service delivery of local governments according to the BV performance indicators. A general evaluation report on the audits will be issued. Auditors in the audit committee will be replaced every 7 years (Audit Commission, 2002, pp.2-3). Auditors will check the availability of performance goals and the credibility of performance changes (Ashworth \& Boyne, 2000). In practice, however, auditors are neglecting the concepts of benchmarking and consultation while more emphasizing competition and challenge. Checklists used by auditors considered poorly performing services, and auditors were more interested in national BV performance indicators than local performance indicators and were also quite reluctant to give good scores (Bovaird, 2008, p.328).

In Scotland, the BV was accepted by the Local Government Act of 2003. It made progress to cover all state ministries and non-ministry institutions. The system was audited by the Performance Management and Planning Auditors appointed by the Scottish Auditing Agency. It was decided to realize auditing for every three to four years with the emphasis on the performance results and the working conditions of the councils, and the results of the audits were submitted to the Scottish Account Commission (CRC, 2002).

In Scotland, the BV inspections were revised in 2009 and emphasis was placed on joint work between local authorities and local service providers (Martin, et al., 2013, pp.277-280). Also, the BV regime was applied between 2000 and 2002 in Wales (Downe, et al., 2010, p.669). The BV approach has been criticized for offering old prescriptions in the form of new ideas such as efficiency. Local administrations have not been able to solve their problems with a holistic approach. Each local government is fo- 
cused on its own problems (Galera, et al, 2008, pp.245-250).

The audit process is based on a bureaucratic template rather than innovative and has met resistance from local governments (Bovaird, 2008, p.336). Most local councils have made limited progress in integrating planning, budgeting, and performance management. Only one-third of the 33 municipal councils were able to determine the appropriate politics for the BV (Midwinter, 2008, p.443).

\subsection{Comprehensive Performance Assessment}

Owing to shortcomings in the BV system, the CPA Program was introduced in 2002. CPA is intended to assess the organizational capacity of a local council and the performance of key services. According to this, the performance of each local administration is proportional to five-point scales from weak to perfect (there is a four-point scale star system after 2005, from no star to 3 stars). At this point, the Labour Party seems to use more influential variables on accountability of political leadership. Attention was paid to the performance management from top to bottom based on the indicators. CPAs are based on the assumption that in the United Kingdom, councils need to define their weaknesses and orient them externally (Martin, et al., 2013, pp.277-280).

CPAs focus on the institutional capacity and performance of councils such as the BV audits. Local governments have been obliged to prepare progress plans defined by auditors (Downe, et al., 2010, p.669; Wollmann, 2004, p.646). Annual performance evaluations have been published for the 150 single tier county councils in the United Kingdom. While evaluation scores are constantly developing, most of the local people are sceptical about developments reported by local administrations. For this reason, the level of satisfaction with local administrations decreased by $11 \%$ between 2001 and 2006 (Downe, et al., 2010, p.668). The government then announced that in 2006, CPAs will be replaced by Comprehensive Area Assessments from 2009 onwards. Thus, the audit committee assessed all service performances based on the local area agreements negotiated by central and local actors in the local strategic partnership. This approach involves a more holistic as- sessment of cost-effectiveness with regard to local services, and it is expected to steadily maintain the services of local strategic partnerships. Performance of local administrations will be guided in more detail through comprehensive area assessments (Bovaird, 2008, p.329). When the local government is compared with the previous year or when the local government is compared with the others, the benefits of performance indicators will increase. Comprehensive area assessments have covered local governments, health, fire, and police services and it required for auditors to make joint negotiations in order to achieve the objectives set out in local area agreements and community strategies (Martin, et al., 2013, pp.277-280). It will enable the identification of the strengths and weaknesses of the local government and to make decisions that will achieve the objectives at optimum cost by comparisons (Galera, et al., 2008, p.245). This is closely related to the fact that in public administration, performance information on outcomes and results is seen as a way of improving accountability. Performance information has become a technique that influences the relationships among the executive, legislative, and public (Midwinter, 2008, p.440). Current performance measures reflect the basic characteristics of local services used by people, as they assess services related to citizen needs (Schachter, 2010, p.556). However, after the 2010 general elections, Secretary of State for Communities and Local Government terminated the comprehensive area assessments and abolished the audit committee. Comprehensive area assessments have been replaced by voluntary programs involving local leaders, administrators, and senior managers (Martin, et al., 2013, pp.277-280).

\subsection{Wales Programme for Improvement}

CPA in Wales was rejected because of publications of the score tables, practices such as disclosure, and blame of weak performers. The WPI has been jointly developed by the Waller National Assembly, the Waller Local Government Association, and the Waller Audit Commission. Self-evaluation and holistic administrative evaluation, taking into account the performance and capacity of each local govern- 
ment, has been at the forefront. Within the context of self-evaluation, each council has agreed on joint risk assessments, which are based on a progression plan and a regulatory plan in line with local priorities (Downe, et al., 2010, p.669). In Wales, public policy makers believed that improvement should be initiated from local councils, not from the center.

The WPI is focused on local priorities and the improvement of each local authority. Unlike the United Kingdom and Scotland, evaluations are based on secret agreements between councils and auditors. BV audits, CPAs, and the WPI have given responsibilities to the local governments to ensure continuous improvement and have authorized the audit bodies of the local authorities. In all three models, it appears that local governments support sustainable development in service outputs with effective leadership and strong performance management systems.

The WPI has suggested that sustainable organizational change depends on local ownership and action. The auditors work in partnership with local councils to identify progress made by local councils (Downe, et al., 2010, p.672). When three approaches are evaluated together, CPAs assume that publishing performance tables will motivate politicians and managers.

In Scotland, politicians have avoided the use of score tables; but they believed that publishing the BV audit reports could be a strong incentive for progress. Public policymakers in Wales have rejected performance comparisons. According to politicians, solid score tables encourage local authorities to cheat and prevent them from explaining performance problems. The Wales regime is not competitive. It does not reward excellent performance and sanctions in poor performance are limited. Even so, in Wales, the 2009 Local Government Act put into effect that councils publish performance data and linked performance assessments to community strategies. Also, The Waller Audit Office will determine if a local authority is making planned progress or how future improvement will be (Martin, et al., 2013, pp.277-280).

Table 2. Performance Evaluation Methods in Local Government in the United Kingdom (Source: Downe, et al., 2010, p.671)

\begin{tabular}{|c|c|c|c|}
\hline Criteria & $\mathrm{CPA}$ & BV & WPI \\
\hline Design and Control & Audit Commission & $\begin{array}{c}\text { Consultation } \\
\text { with Local Governments } \\
\text { and Scottish Audit Agency }\end{array}$ & $\begin{array}{l}\text { The Wales Audit Commission, } \\
\text { The Wales Local Government } \\
\text { Association, } \\
\text { The Wales National Assembly }\end{array}$ \\
\hline Leadership Theory & $\begin{array}{l}\text { Institutional capacity } \\
\text { and leadership }\end{array}$ & $\begin{array}{l}\text { Institutional capacity } \\
\text { and leadership }\end{array}$ & $\begin{array}{l}\text { Institutional capacity } \\
\text { and leadership }\end{array}$ \\
\hline $\begin{array}{c}\text { Individual Motivation } \\
\text { Theory }\end{array}$ & Competitive & Semi-competitive & Non-competitive \\
\hline $\begin{array}{l}\text { Theory of Organiza- } \\
\text { tional Change }\end{array}$ & $\begin{array}{l}\text { External support } \\
\text { for internal behaviors }\end{array}$ & $\begin{array}{l}\text { Initiating and collaborating } \\
\text { with change externally }\end{array}$ & Internal ownership \\
\hline $\begin{array}{l}\text { Accountability } \\
\text { theory }\end{array}$ & Ministers and public & People and local politicians & Local politicians \\
\hline $\begin{array}{c}\text { Sensitivity } \\
\text { to local conditions }\end{array}$ & Low & Middle & High \\
\hline Intervention mode & $\begin{array}{l}\text { Dramatic, open, } \\
\text { responsive }\end{array}$ & Open and public & Reluctant, based on consent \\
\hline
\end{tabular}


In the case of CPAs, poorly performing local authorities have been passive without solving its performance problems. BV audits in Scotland have encouraged external control for organizational change; but it has a different approach to CPAs that seek a compromise between city councilors and auditors (Downe, et al., 2010, pp.670-672).

CPAs have sought to improve the accountability of ministers and local authorities. The publication of the BV audit reports has enabled the public to effectively and directly account for local authorities. In Wales, necessary changes were made to the local authorities through risk assessments (Downe, et al., 2010, p.672).

Table 2 summarizes CPA models applied in local governments in the United Kingdom.

\section{Discussion}

This study focuses on the difficulties of performance management in the implementation of the local area and how to overcome them. There are various difficulties determining the criteria to be used in performance management in public administration and evaluating performance according to objective administrative criteria. In the case of United Kingdom, performance in the local area is an indication of this.

The determination and control of performance criteria by the central authority could not provide the effectiveness of local services. The instability and failure of local performance systems make it necessary to establish performance models based on the preferences of local actors. The identification of individual performance criteria for each local government and the citizen-oriented assessment of the performance of the local government emphasize the importance of a governance model in public administration.

\section{Conclusion}

Performance management is one of the important tools used to increase the economic rationality in public administration. Performance management aims to provide efficiency and effectiveness in public institutions and increases professional accountability. Performance management requires defining organizational goals and objectives, establishing performance targets, and measuring individual and organizational performance. Identification of performance indicators and audit standards in the design of the performance management system, especially in public administration, are important for achieving strategic results. Short-term targets should also be reviewed while performance indicators are set. Performance data should be recorded objectively.

An organizational culture that encourages flexibility and innovation should be adopted.

In the United Kingdom, local reflections of performance management are based on the performance measurement systems supported by the central administration. The BV in 1999 was put into effect for local governments in United Kingdom and Wales. The BV requires that the local governments establish their performance targets and maintain efficiency according to these goals. This process is supported by the audit committee controlling local service delivery.

In Scotland, the BV Practice was accepted in 2003 with Local Governments Act. The BV in Wales was implemented between 2000 and 2002. However, the BV has not been able to solve the problems of the local administrations holistically. The audit process focuses on bureaucratic issues rather than pursuing innovative developments. Owing to deficiencies in the BV system, CPAs were introduced in 2002, which evaluated the institutional capacity and performance of local councils annually. In this system, evaluation scores improved, but the local people approached performance reports sceptically.

Upon this, in 2009, CPAs were launched, aiming at the holistic assessment of local service performance by central and local actors. However, after 2010, this practice was abolished and local governments decided to measure performance through voluntary programs. This practice is based on a governance approach. Administrative performance is guided democratically by the common negotiations of local actors. In Wales, CPAs were rejected for reasons such as the publication of score tables, the disclosure, and condemnation of weak performers. Later, it became possible to explain performance data through the local administration act 2009. 
In Wales, holistic administrative evaluations and a self-assessment system are at the forefront in assessing the performance of local administrations. Generally, the local performance model in the United Kingdom is based on the effective leadership mechanisms and strong performance management systems. It focuses on system outputs and is focused on sustainable development. Performance systems applied at the local scale seem to make a positive contribution to administrative accountability.

The publication of BV audit reports has increased transparency and has allowed the public to establish direct control over local authorities. CPAs have increased the professional and managerial accountability of ministers and local authorities. In Wales, the performance of local administrations is assessed objectively through risk assessments. It can be said that frequent changes in performance evaluation systems negatively affects the stability of the system. Another problem experienced in practice is to ensure that performance systems based on different standards achieve consistent results.

The following conclusions can be drawn from an example from the United Kingdom: Centralized performance measurement systems at local level performance measures have not developed consistently. The frequent intervention of the central audit agency in the process of assessing the performance of local administrations has led to bureaucratization and inefficiency. In assessing performance at local scale, it is necessary for local actors to agree on performance criteria together.

Whether the performance targets have been achieved should be assessed directly from the local people's point of view. The expectations and evaluations of local people for the quality of local service provided will ensure the accountability of the local councils in professional and administrative terms.

It is important that all actors in the system take part in the success of performance management in local administrations. For this, a strategic plan should be prepared in line with local values. Regular training should be provided to the staff who will implement the performance system.

The participation of local people and nongovernmental organizations in administrative pro- cesses should be ensured in determining performance criteria and evaluating performance outcomes.

\section{$7 \quad$ References}

[1] Ashworth, R., Boyne, G., 2000. Promises and Performance, (edt. by T. Clark and K. Hoggart). People, Parties and Policies, Westview, Boulder.

[2] Audit Commission, 2002. Stewardship and Governance: A Review of the work of the Audit Commission's Appointed Auditors in 2002.

[3] Auguinis, H., Gottfredson, R.K., Joo, H., 2013. Avoiding a "me" versus "we" dilemma: Using Performance Management to Turn Teams into a Source of Competitive Advantage. Business Horizons, 56, pp.503-512.

[4] Auguinis, H., Gottfredson, R.K., Joo, H., 2012a. Using Performance Management to Win the Talent War. Business Horizons, 55, pp.609-616.

[5] Auguinis, H., Joo, H., Gottfredson, R.K., 2012b. Performance Management Universals: Think Globally and Act Locally. Business Horizons, 55, 385-392.

[6] Boyne, G., 2001. The Impact of Best Value on Local Authority Performance: Evidence from the Welsh Pilots. Local Government, 27 (2), pp.44-68.

[7] Boyne, G.A.,. Gould-Williams, J., Law, J. and Walker, J., 2002. Plans, Performance Information and Accountability: the Case of Best Value. Public Administration, 80 (4), pp.691710.

[8] Bovaird, T., 2008. Emergent Strategic Management and Planning Mechanisms in Complex Adaptative Systems: The Case of UK Best Value Initiative. Public Management Review, 10(3), pp.319-340.

[9] CRC for Construction Innovation (2002). Best Value Second Interim Report. CRC for Construction Innovation, Brisbane.

[10] Cuganesan, S., Guthrie J., Vranic, V., 2014. The Riskiness of Public Sector Performance Measurement: A Review and Research Agenda. Financial Accountability \& Management, 30 (3), pp.279-302. 
[11] DETR, 1999. Best Value: New Roles for Members, London: DETR.

[12] Fryer, K., Antony J., Ogden S., 2009. Performance Management in the Public Sector. International Journal of Public Sector Management, 22 (6), pp.478-498.

[13] Harris, L., 2005. UK Public Sector Reform and Performance Agenda in UK Local Government: HRM Challenges and Dilemmas. Personnel Review, 34 (6), pp.681-696.

[14] Lin Shin-Jie and Po-Yu Lee, 2011. Performance Management in Public Organizations: A Complexity Perspective. International Public Management Review, 12 (2), pp.81-96.

[15] Martin, S., Downe, J., Grace, C., Nutley S., 2013. All Change? Performance Assessment Regimes in UK Local Government. Public Money \& Management, 33 (4), pp.277-280.

[16] Martin, S., 2002a. Best Value: New Public Management or New Direction (edt. by Kate McLaughlin, et al.). New Public Management: Current Trends and Future Prospects. London: Routledge, pp.129-141.

[17] Martin, S., 2002b. The Modernization of UK Local Government: Markets, Managers, Monitors and Mixed Fortunes. Public Management Review, 4 (3), pp.291-307.

[18] Martin, S. 2000. Implementing Best Value: Local Public Services in Transition. Public Administration, 78 (1), pp.209-227.

[19] Midwinter, A., 2008. Performance Management and Best Value Audit in Scotland: A Research Note on Theory and Practise. Financial Accountability \& Management, 24 (4), pp.439-453.

[20] Mueller-Hanson, R., Pulakos E.D., 2015. Putting the Performance Back in Performance Management. Shrm-SIOP Science of HR White Paper Series, pp.1-25.

[21] Navarro-Galera, A., Orti-Rodriguez, D., and López-Hernández, A.M., 2008. Identifying Bar- riers to the Application of Standardized Performance Indicators in Local Government. Public Management Review, 10 (2), pp.241-262.

[22] Nielsen, P.A., 2013. Performance Management, Managerial Authority and Public Service Performance. Journal of Public Administration Research and Theory, 24, pp.431-458.

[23] Pulakos, E.D., Mueller-Hanson, R.A., O’Leary, R.S., Meyrowitz M.M., 2012. Building a HighPerformance Culture: A Fresh Look At Performance Management. Alexandria, VA: Society for Human Resource Management.

[24] Pulakos, E.D., Mueller-Hanson, R.A., Arad, S., Moye, N., 2015. Performance Management Can Be Fixed: An On-the-Job Experiential Learning Approach for Complex Behaviour Change. Industrial and Organizational Psychology, 8 (1), pp.51-76.

[25] Sanderson, I., 2001. Performance Management, Evaluation and Learning in Modern Local Government. Public Administration, 79 (2), pp.297313.

[26] Schachter, H.L., 2010. Objective and Subjective Performance Measures: A Note on Terminology. Administration \& Society, 42 (5), pp.550-567.

[27] Stevens, P., Stokes, L., O'Mahony, M., 2006. Metrics, Targets and Performance. National Institute Economic Review, Vol. 197, July, pp.8092.

[28] Vakkuri, J., Meklin P., 2006. Ambiguity in Performance Measurement: A Theoretical Approach to Organizational Uses of Performance Measurement. Financial Accountability \& Management, 22 (3), pp.235-250.

[29] Wollman, H., 2004. Local Government Reforms in Great Britain, Sweden, Germany, and France: Between Multi-Function and Single- Purpose Organizations. Local Government Studies, 30 (4), pp.639-665. 